\title{
EIחतA
}

Revista Eletrônica de Estudos Integrados em Discurso e Argumentação

\section{POR QUE OS EDUCADORES DEVEM PREOCUPAR-SE COM ARGUMENTAÇÃO?}

\author{
Harvey Siegelii
}

Resumo: Educadores que refletem sobre suas práticas educacionais fazem a si mesmos perguntas como: Qual é o objetivo da educação? Quais coerções morais, metodológicas ou outras guiam nossas atividades e esforços educacionais? Um lugar natural para procurar por respostas é a Filosofia da Educação, a qual (dentre outras coisas) tenta fornecer respostas sistemáticas para essas questões. Uma resposta comum dada pela Filosofia da Educação é que o objetivo da educação consiste em fomentar o desenvolvimento da racionalidade dos alunos. Nesse ponto de vista, a educação tem como tarefa fundamental tanto o desenvolvimento da capacidade de raciocínio, quanto a formação de um complexo de atitudes, de hábitos da mente, de disposições e de marcas de caráter, de modo que os estudantes sejam capazes não apenas de raciocinar bem, mas também de se importarem acerca das razões e de organizarem suas crenças, julgamentos e ações em consonância com a avaliação racional das razões. A Teoria da Argumentação também se ocupa da análise do poder e da força de convencimento do raciocínio. Quando as razões para uma alegação justificam a aceitação dessa alegação? Sob quais critérios os raciocínios são avaliados? Como esses critérios são justificados? Questões como estas são o arroz e o feijão $o^{\text {iii }}$ da Teoria da Argumentação, que, na procura de respostas, promete clarear o caráter da racionalidade como o objetivo da educação. A racionalidade, que conecta a educação à Teoria da Argumentação, fornece aos educadores uma razão para se preocuparem com argumentação - se ela puder ser convincentemente defendida enquanto um ideal educacional. Neste artigo, tentarei defender essa ideia e, assim, explicar por que educadores devem se preocupar com a argumentação. A defesa será moral: vou defender que somos moralmente obrigados a nos esforçar para promover a racionalidade dos estudantes, porque isso é necessário para satisfazer nossas obrigações de tratar os alunos respeitosamente como pessoas. Também considerarei algumas críticas gerais aos ideais iluministas de racionalidade, advindos de pesquisadores do Feminismo, do Multiculturalismo e do Pós-modernismo. Se tais críticas procedem, então tanto a Teoria da Argumentação quanto a visão de que a educação deve ter como objetivo fomentar a racionalidade encontram-se ameaçadas. Vou argumentar que tais críticas, embora importantes e instrutivas, não são tão destrutivas do ideal de racionalidade como alguns estudiosos contemporâneos sugerem.

Palavras-chave: Argumentação. Educação. Objetivos educacionais. Racionalidade.

\footnotetext{
i Referência da publicação original: SIEGEL, Harvey. Why Should Educators Care about Argumentation? Informal Logic, Windsor, v. 17, n.2, p. 159-176, 1995.

ii Doutor em Educação pela Universidade de Harvard e docente da University of Miami, Estados Unidos. E-mail: hsiegel@miami.edu.

iii N.T. Na versão original em inglês, "Such questions as these are the meat and potatoes of argumentation theory".
} 


\title{
EIחतA
}

Revista Eletrônica de Estudos Integrados em Discurso e Argumentação

\section{POR QUE OS EDUCADORES DEVEM PREOCUPAR-SE COM ARGUMENTAÇÃO?}

\author{
Harvey Siegel
}

\begin{abstract}
Educators who are reflective about their educational endeavours ask themselves questions like: What is the aim of education? What moral, methodological or other constraints govern our educational activities and efforts? One natural place to look for answers is in the philosophy of education, which (among other things) tries to provide systematic answers to these questions. One general answer offered by the philosophy of education is that the aim of education consists in fostering the development of student's rationality. On this view, education has as its fundamental task both the development of student's reasoning ability, and also the fostering of a complex of attitudes, habits of mind, dispositions and character traits, such that students are not only able to reason well; they also care about reasons, and organize their beliefs, judgments and actions in accordance with the deliverances of the reasoned evaluation of reasons. Argumentation theory is also concerned with the analysis of the power and convicting force of reasons. When do reasons for a claim warrant acceptance of that claim? By what criteria are reasons evaluated? How are these criteria themselves justified? Such questions as these are the meat and potatoes of argumentation theory, which, in pursuing these questions, promises to shed light on the character of rationality as the aim of education. Rationality, which links education and argumentation theory, provides educators with a reason to care about argumentation - if rationality can be cogently defended as an educational ideal. In this paper I will try to provide such a defense, and in doing so explain why educators should care about argumentation. The defense will be a moral one: I will argue that we are morally obliged to endeavour to foster the rationality of students, because that is what is required to meet our obligations to treat students with respect as persons. I will also consider some general criticisms of the Enlightment ideal of rationality, offered by Feminist, Multiculturalist, and Postmodernist scholars. If these criticisms are cogent, then both argumentation theory and the view that the aim of education is fostering of rationality are threatened. I will argue that the criticisms, while important and instructive, are not so destructive of the ideal of rationality as some contemporary scholars suppose.
\end{abstract}

Keywords: Argumentation. Education. Educational aims. Rationality. 
EID\&A - Revista Eletrônica de Estudos Integrados em Discurso e Argumentação, Ilhéus, n. 11, jan/jun.2016.

\section{Introdução}

Educadores são pessoas ocupadas. Eles precisam se preocupar com a conduta e a disciplina em sala de aula, com a autoestima dos estudantes, com construção política e sistemas políticos, com as atitudes e o envolvimento dos pais (ou a falta dele), com maus administradores e professores, com financiamento e também com outras milhões de coisas. Por que, então, deveriam se preocupar com a argumentação?

A seguir, discutirei que eles devem se importar e tentarei explicar o porquê disso.

\section{Com o que educadores devem se preocupar?}

Como é típico na filosofia - e também nesse caso -, para responder satisfatoriamente dada questão, é necessário voltar a atenção para uma questão prévia. Para saber se educadores necessitam lidar com a argumentação em particular, precisamos primeiramente descobrir com o que eles devem se preocupar de modo geral. Então, saberemos se a argumentação está inclusa nesse conjunto mais amplo das preocupações educacionais legítimas. Portanto, com o que educadores devem se preocupar?

Obviamente, eles devem se preocupar com muitas coisas. Antes de mais nada, educadores são pessoas que se preocupam ao menos com todas as coisas que pessoas geralmente devem se preocupar: fome, paz mundial, se o recém-inventado Teorema de Fermat foi bem sucedido, se haverá uma World Series esta temporada - e, se houver, se os Blue Jays irão vencê-la - etc. Porém, essas preocupações, legítimas e importantes, claramente nada têm a ver com nossa questão. Assim, precisamos refiná-la um pouco. Devemos perguntar: o que educadores, enquanto educadores, devem se preocupar?

A primeira resposta é óbvia: educadores, enquanto educadores, devem se preocupar com a educação. A despeito de quão importante possa ter sido a greve de árbitros e o locaute dos proprietários da Major League Baseball, uma vez que se projetava que os Blue Jays não só não jogariam em casa nesta temporada, mas o fariam em uma terra estrangeira e hostil, é claro que isso não são preocupações de educadores enquanto educadores, na medida em que não estão diretamente ligadas à educação.

Assim, educadores, enquanto educadores, devem se preocupar com a educação. Até aí, sem problemas. Mas isso não nos diz muito, já que a 
EID\&A - Revista Eletrônica de Estudos Integrados em Discurso e Argumentação, Ilhéus, n. 11, jan/jun.2016.

educação possui várias camadas e é uma atividade multifacetada. Eles deveriam se preocupar com os delitos dos alunos? Claro. Com o novo layout arquitetônico proposto às salas de aula do ensino médio? Obviamente. A lista poderia se estender indefinidamente. O que une todas essas preocupações educacionais legítimas é a sua relação com o objetivo da atividade: elas são preocupações legítimas da educação por conta de seu de seu impacto sobre nossa habilidade de alcançar nossos fins educacionais.

Consequentemente, uma preocupação central e permanente dos educadores enquanto educadores envolve a natureza desses fins. O que nós estamos tentando realizar quando nos engajamos em nossas atividades educacionais? Quais fins estamos tentando realizar e como deveríamos tentar alcançá-los? As preocupações legítimas dos educadores enquanto educadores depende dos fins, objetivos e ideais da educação. Portanto, uma preocupação fundamental dos educadores enquanto educadores se refere à natureza desses objetivos e ideais. O que eles são? E porque são esses, e não outras coisas, nossos derradeiros objetivos educacionais, isto é, como nossos objetivos e ideais educacionais justificam a si mesmos?

Estas questões estão entre as mais básicas da Filosofia da Educação. Então, como será discutido posteriormente, podemos dizer que educadores enquanto educadores devem estar preocupados com questões filosóficas sobre educação, especialmente aquelas concernentes à natureza e justificativa dos objetivos e ideais básicos da educação.

Então, quais são nossos objetivos e ideais básicos da educação? Embora os filósofos tenham, ao longo da história desta matéria, abordado a questão, eles não o têm feito de modo uníssono. Muitos ideais pressupostos têm avançado: criatividade, cidadania, várias concepções de bom caráter, autoconfiança, autoestima, autoimagem positiva, obediência a (em geral, seletos) outros, obediência às leis morais, preocupação com o próximo, reverência e devoção a Deus, vários tipos de conhecimentos, sensibilidade estética, entre outros. Felizmente, para todos nós, não é o momento de verificar ou avaliar os pontos fortes e fracos desses diversos ideais educacionais propostos. Para fazer isso, precisaríamos nos dispersar do nosso assunto, a argumentação. Em vez disso, prefiro me focar em um ideal educacional em particular - de caráter fundamental -, que, como discutirei, está intimamente relacionado à argumentação: a racionalidade. 
EID\&A - Revista Eletrônica de Estudos Integrados em Discurso e Argumentação, Ilhéus, n. 11, jan/jun.2016.

A ideia de que a educação deve, fundamentalmente, preocupar-se com o desenvolvimento da racionalidade é uma proposta com um distinto e longo pedigree na história da filosofia ocidental da educação. Em vários períodos e com várias ênfases e enfoques, isso tem sido defendido pela vasta maioria dos filósofos da educação na tradição intelectual ocidental, incluindo Sócrates, Platão, Aristóteles, dentre outros da Antiguidade; Anselmo, Aquino, Escoto e outros importantes Filósofos medievais; Locke Hume, Kant, Rousseau, Mill e outros do período iluminista e moderno; e, neste século, por, entre outros, Bertrand Russell, John Dewey, R.S. Peters e Israel Scheffler' ${ }^{1}$.

Embora, certamente, não me coloque ao lado destas altaneiras figuras filosóficas, tenho defendido que fomentar a racionalidade dos estudantes é um objetivo educacional fundamental e tenho tentado em vários lugares articular e justificar esse ideal ${ }^{2}$. A seguir, devo dizer um pouco mais sobre este ideal e sua justificativa, de modo a esclarecer sua conexão fundamental com a argumentação.

Dizer que a racionalidade é um objetivo ou ideal fundamental da educação é dizer que as atividades educacionais devem ser concebidas, definidas e executadas de modo a conduzir, ceteris paribus, ao máximo desenvolvimento da racionalidade dos estudantes. Em que a racionalidade consiste? Resumidamente, em dois aspectos independentes: na habilidade de avaliar argumentos e em um complexo de atitudes, disposições, hábitos da mente e marcas de caráter que pode ser definido coletivamente como espírito crítico.

O primeiro aspecto envolve a habilidade dos estudantes de avaliar as forças epistêmicas dos fundamentos que podem ser oferecidos em apoio a possíveis crenças, alegações e julgamentos - isto é, ser capaz de distinguir entre razões que genuinamente os apoiam ou não e, nos casos em que apoiam, ser capaz de determinar a força deste apoio. Uma pessoa é racional apenas na medida em que pode, entre outras coisas, avaliar sistemática e apropriadamente essas razões. Quando nós afirmamos que a racionalidade é um ideal fundamental da educação, defendemos que a educação deve lutar para fomentar nos estudantes as habilidades que permitirão uma avaliação competente das razões.

\footnotetext{
1 Para uma breve discussão desta história, ver Siegel (1992, p. 108-109).

${ }^{2}$ Mais sistematicamente em Siegel (1988).
} 
EID\&A - Revista Eletrônica de Estudos Integrados em Discurso e Argumentação, Ilhéus, n. 11, jan/jun.2016.

O segundo aspecto - o espírito crítico - envolve o caráter do aluno. Aquele que possui espírito crítico não é apenas capaz de avaliar bem as razões; ele também está disposto a fazê-lo, e a conformar suas crenças, julgamentos e ações ao resultado dessas avaliações. Ele tem, como admiravelmente pontuou o Professor Binkley, um "amor pela razão" (BINKLEY, 1980, p. 83), e sua vida inteira é moldada por esta visão sobre a razão e o seu valor. Quando dizemos que a racionalidade é um ideal fundamental da educação, afirmamos que esta educação deve lutar para que os alunos desenvolvam o complexo de atitudes, disposições, hábitos da mente e marcas de caráter constitutivo do espírito crítico3.

A próxima questão óbvia a se fazer é: por que nós devemos considerar a racionalidade, conforme discutida, como um ideal fundamental da educação? Temos razão para justificá-la como tal? Embora eu acredite que haja uma variedade de considerações que argumentam em favor de considerá-la como tal, a fundamental é de teor moral: nós somos moralmente obrigados a tratar os estudantes de modo a fomentar o desenvolvimento de sua racionalidade, porque, apenas tratando-os deste jeito, honraremos a prescrição Kantiana de tratá-los com respeito como pessoas 4 (Esta referência à visão "iluminista" de Kant sobre a importância do indivíduo e de sua autonomia tem sido objeto de sérias críticas ultimamente; vamos considerá-las mais adiante.)

Por fim, antes de retomarmos nossas considerações sobre argumentação, gostaríamos de destacar o caráter normativo da concepção de racionalidade esboçado. A racionalidade, concebida como um ideal educacional, é, em pelo menos dois aspectos, normativa. Primeiro, obviamente, coloca um enorme valor positivo na racionalidade; o defensor desse ideal classifica-o como mais elevado do que pelo menos vários ideais educacionais alternativos. Entretanto, de forma mais relevante para a presente discussão, ela é a normativa em sua abordagem ao que podemos chamar de substância da educação: o defensor deste ideal que é importante que os alunos raciocinem bem e considera fundamental a tarefa educacional de ajudar os estudantes a maximizar (ceteris paribus) sua habilidade para isso. Estudantes que raciocinam mal podem não estar à altura desse ideal. Este é o aspecto normativo deste que nos permite construir uma ponte entre ele e a

\footnotetext{
3 Para uma discussão mais aprofundada dessas duas dimensões do ideal, ver o capítulo 2 de Siegel (1988).

4 Para uma discussão mais aprofundada do problema de justificar a racionalidade como um ideal educacional fundamental, ver o capítulo 3 de Siegel (1988).
} 
EID\&A - Revista Eletrônica de Estudos Integrados em Discurso e Argumentação, Ilhéus, n. 11, jan/jun.2016.

argumentação. Enfim, estamos preparados para considerar a conexão entre educação e argumentação viabilizada pelo ideal de racionalidade.

\section{Educação e argumentação}

A argumentação - independente do que possa ser - tem por objetivo uma resolução racional de questões, assuntos e disputas. Quando nos engajamos em uma argumentação, não procuramos simplesmente resolver desacordos ou questões excepcionais de qualquer maneira - se assim o fizéssemos, instâncias de lavagem cerebral, de manipulação do interlocutor para ingerir produtos químicos apropriados e realizações de ameaças físicas contariam como episódios de argumentação, uma vez que estas são formas de resolver questões e disputas. Tais maneiras de forjar resoluções são acertadamente rejeitadas como instâncias de argumentação, justamente porque não são racionais: isto é, tais procedimentos não proporcionam confiança de que a resolução alcançada é, de alguma forma, racionalmente superior ou preferível a outra resolução possível. A argumentação, portanto, concerne a/é dependente da bondade, do status normativo ou da força epistêmica, de razões candidatas à crença, ao julgamento e à ação5

Quando a argumentação é concebida dessa forma, então a teoria da argumentação é, de modo semelhante, concebida como uma exploração de questões, tais como: sob quais condições episódios de argumentação são bem sucedidos? Isto é, sob quais condições resoluções de disputas racionais são alcançadas? Por quais critérios tal racionalidade é determinada?

Assim entendida, a argumentação e sua teoria são fundamentalmente preocupadas com a racionalidade e com a avaliação normativa do argumento. Como tal, a argumentação e a teoria da argumentação (e a lógica informal) são do interesse direto dos educadores, uma vez que, como vimos, educadores - pelo menos aqueles que abraçam o ideal da racionalidade desenvolvem suas atividades educacionais de forma a (ceteris paribus) promover o máximo da racionalidade de seus alunos. Educadores enquanto educadores querem que seus alunos sejam capazes de argumentar bem - não no sentido sofístico de ser capaz de "vencer" argumentações em virtude de

\footnotetext{
5 Essa visão epistêmica de argumentação é articulada em Biro \& Siegel (1992) e Siegel \& Biro (1995). Ao conceber a argumentação desta forma, difiro-me de Binkley (1995), que atribui à lógica a tarefa de estabelecer padrões para a correção (correctness) de raciocínio, negando que a argumentação envolva qualquer dimensão epistêmica, normativa.
} 
EID\&A - Revista Eletrônica de Estudos Integrados em Discurso e Argumentação, llhéus, n. 11, jan/jun.2016.

seus poderes de persuasão, mas no sentido de serem guiados por boas razões de modo que suas crenças, julgamentos e ações sejam nelas baseados. Da mesma forma, educadores querem que seus alunos compreendam por que determinadas razões para crença, julgamento e ação são epistemologicamente mais fortes do que outras e entendam os critérios pelos quais tais avaliações são feitas, bem como a maneira pela qual tais critérios são justificados. E para esses objetivos educacionais, a argumentação e sua teorização são diretamente relevantes. Em resumo, uma vez que educadores almejam que seus alunos tanto argumentem bem quanto entendam a constituição de um bom argumento, eles devem estar interessados na teoria e na prática da argumentação.

A educação e a argumentação estão unidas, dessa forma, pelo seu interesse mútuo com a racionalidade e as dimensões normativas das razões e do raciocínio. Dado que a argumentação e sua teorização prometem ajudar a alcançar - assim como fornecer informações a respeito da constituição de - o objetivo dos educadores de promover o desenvolvimento da racionalidade, este deve preocupar-se com a argumentação e sua teoria. Temos aqui a resposta à nossa pergunta inicial: educadores devem se preocupar com a argumentação devido à estreita conexão entre o ideal educacional de racionalidade e as preocupações e as dimensões normativas da argumentação e da teoria da argumentação.

Seria bom se a minha história pudesse ser levada a um fim aqui. Expliquei os motivos pelos quais os educadores devem se preocupar com a argumentação. O item principal em minha explicação é o compromisso dos educadores com o ideal da racionalidade que forja, por sua vez, a ligação entre a argumentação e a educação. No entanto, seria descuido ignorar o fato de que, no momento, o ideal da racionalidade está em descrédito em diversos círculos. Assim, minha explicação apenas terá sucesso se eu puder neutralizar críticas recentes desse ideal. Essa é a tarefa de que tratarei adiante.

\section{Os desafios recentes da racionalidade como um ideal educacional digno}

Neste mundo pós-moderno, há problemas para a racionalidade. Anteriormente, tentei justificar brevemente $\mathrm{o}$ ideal educacional da racionalidade nos termos kantianos do princípio moral de respeito pelas pessoas. Porém, não é segredo que muitos críticos da filosofia "liberal", "iluminista”, rejeitam o individualismo e o valor da autonomia racional, 
aparentemente pressuposto pelo princípio de Kant. Mais fundamentalmente, muitos críticos do projeto iluminista rejeitam completamente a valorização modernista da racionalidade. Se eles estiverem corretos, então o ideal educacional da racionalidade passa aparentemente pelo conselho e, com ele, minha explicação dos motivos pelos quais os educadores devem preocupar-se com argumentação. Assim, a fim de fazer uma boa explicação, devo tentar dissuadir as críticas existentes sobre a racionalidade.

A literatura crítica aqui é vasta, e não posso esperar terminar o trabalho completamente, ou mesmo abordá-lo de forma adequada, no espaço limitado restante. Tentarei mostrar, contudo, que há razão para pensar que o ideal da racionalidade pode sobreviver intacto a, pelo menos, algumas críticas. Considerarei, então, algumas delas.

\subsection{A linguagem é muito instável para licenciar o ideal}

Jacques Derrida é famoso por apontar para a "indeterminação" da linguagem e do significado linguístico e, nas palavras de Rene Arcilla6, para "a escravidão da aporia na linguagem"7. Em uma excelente discussão sobre Derrida e sobre as implicações de suas visões de linguagem para a filosofia da educação no ensino geral e, em especial, na educação multicultural, Arcilla (1995) sugere que essas implicações são sinistras para os objetivos filosóficos tradicionais da educação:

[...] embora os filósofos continuem a tecer discursos a fim de adiar a indeterminação, essa indeterminação, como uma força da natureza, é fadada a voltar e assombrar termos no discurso. Uma vez alterados e alienados de seu contexto, estes termos agora questionáveis estão provocando novas bocas para desfiar o velho discurso e outra geração de canetas para declarar a independência a partir de seus termos. Assim, a filosofia se perpetua. No entanto, o mesmo ocorre com a indeterminação, que continua a ser a condição para a possibilidade de chamar diferentes pensadores para o diálogo que mantém a filosofia viva (ARCILLA, 1995, p. 168-169)

A linguagem é aporética, indeterminada tal como Derrida e Arcilla sugerem? Se assim for, quais as consequências concernentes a um ideal de racionalidade educacional? Eu argumentaria, em primeiro lugar, que qualquer

${ }^{6}$ N.T. Na versão original em inglês, "the thrall of aporia in language".

7 Esta discussão é extraída de Siegel (1995a). Tomei descaradamente minha discussão naquele artigo, que concerne principalmente ao tratamento do autoconhecimento em Arcilla, e transferi meus pontos de vista para a presente discussão sobre ideais educacionais. Embora um pouco incomum, acredito que a transferência foi bem-sucedida. As referências relevantes aos textos de Derrida são fornecidas neste artigo. 
EID\&A - Revista Eletrônica de Estudos Integrados em Discurso e Argumentação, Ilhéus, n. 11, jan/jun.2016.

afirmação sobre a indeterminação da linguagem arruinar ou esse ou qualquer outro ideal educacional é, em si, arruinada pelo fato de que a indeterminação relevante, se genuína, aplicar-se-ia à afirmação em si. Não vejo por que a indeterminação e a aporia, que são acusadas de arruinar a busca modernista por ideais educacionais, também não impingem, e enfraquecem, essa mesma visão de linguagem que, supostamente, causa danos aos ideais, uma vez que a tese de Derrida parece depender do estabelecimento definitivo da indeterminação (a saber: "Eu, Derrida, estabeleci definitiva e firmemente, por meio da linguagem, que toda linguagem e todo significado são indeterminados"). Deixe-me ampliar este ponto um pouco.

Primeiro, considere a forma básica do argumento de Arcilla:

(1) A linguagem é provisória e indeterminada.

(2) Portanto, o diálogo é interminável.

(3) Portanto, ideais filosóficos, que dependem do diálogo, são indeterminados, inconclusivos e sujeitos a perturbações.

O primeiro item, premissa fundamental, expressa a afirmação de Derrida sobre a natureza aporética da linguagem. Devemos aceitar essa premissa? Não, eu não acho, sem qualificação. A qualificação é necessária porque, sem ela, a alegação expressa está sujeita a um acúmulo de dificuldades: se a linguagem tem apenas sentido provisório e é indeterminada, então, a premissa que expressa a alegação é em si apenas provisória e indeterminada. Porém, se assim for, a afirmação é, pelo menos em certa medida, prejudicada porque sua grande declaração acerca da natureza da linguagem é (para dizer o mínimo) significativamente limitada. Em outras palavras, se a linguagem e o significado são, em geral, provisórios e indeterminados, então também o são a expressão linguística e o significado da própria alegação de Derrida. No entanto, se assim for, então, em primeiro lugar, nenhum dos itens supracitados, (2) e (3), resultam dela; e, em segundo lugar, ela é incapaz de minar a possibilidade de estabelecer a racionalidade como um ideal educacional legítimo. $\mathrm{O}$ fato de a tese de Derrida relativa à aporia aplicar-se a si mesma mina sua própria habilidade de fazer o trabalho que se solicita que ela faça.

Segundo, a autoaplicabilidade da tese de Derrida suscita outra dificuldade. Será que "sabemos" que a linguagem é aporética? Como poderíamos saber se a linguagem é, de fato, aporética? Isso depende, claro, do que queremos dizer com "conhecimento". Se a tese é de que a 
EID\&A - Revista Eletrônica de Estudos Integrados em Discurso e Argumentação, Ilhéus, n. 11, jan/jun.2016.

compreensão da linguagem é tão boa quanto qualquer outra, então não podemos saber qualquer alegação expressa em linguagem; isto, obviamente, aplica-se à própria tese, bem como para todo o resto. Esta é uma receita para o ceticismo epistemológico, baseada em um ceticismo linguístico derridadiano concernente ao significado. Não irei pausar aqui para considerar os méritos de tal ceticismo. No entanto, a tese não necessita ser lida desta forma rígida; considero que isso é mais plausivelmente compreendido como uma forma de recomendação de falibilidade ao invés de ceticismo, a saber: uma vez que a linguagem está sujeita à aporia, é sempre possível que, acerca daquilo que nós pensamos que sabemos (tomemos o exemplo de Arcilla, o de que ele é um homem), se possa, em algum ponto, decidir que não se saiba. Dada a sempre presente possibilidade de novos conhecimentos, novas teorias, novas evidências e novos alinhamentos de significado, devemos sempre manter aberta a possibilidade de que nossas potenciais alegações de conhecimento possam ser revistas. Que o conhecimento seja, em princípio, passível de revisão não leva ao ceticismo, mas apenas à falibilidade. Por esse ângulo, podemos saber, falivelmente, que a linguagem é aporética (Se, de fato, sabemos isso, é, com certeza, outra questão.) Porém, isso só é possível se não mantivermos a ideia de que uma compreensão da linguagem é tão boa tanto quanto qualquer outra; mas, sim, que a compreensão derridadiana da linguagem como aporética - ainda que passível de revisão - é a melhor compreensão de que dispomos atualmente. Aqui, conhecimentos, entendimentos e significados admitem avaliações em termos de melhor e pior. Esse tipo de interpretação - falível, mas não-cética - é o que derridadianos exigem, se seus argumentos sobre qualquer coisa são pautados na premissa (1) de Derrida. Contudo, se assim for, então, como afirmei acima, essa premissa é realmente muito mais fraca do que aparenta. Na verdade, nenhuma menção da premissa é necessária: todos nós somos agora "falibilistas" e assim tem sido desde Peirce. A discussão e a tese de Derrida, entendida falibilisticamente, em nada contribui. Entendida de maneira cética, ela destrói a si mesma e, portanto, também em nada contribui. De qualquer maneira, então, a tese de Derrida é muito menos impressionante do que parece à primeira vista. Tal tese não tende, portanto, a enfraquecer tanto a busca, em geral, de ideais educacionais, quanto o estabelecimento da racionalidade como ideal educativo fundamental particularmente. 
EID\&A - Revista Eletrônica de Estudos Integrados em Discurso e Argumentação, Ilhéus, n. 11, jan/jun.2016.

\title{
3.2. "Metanarrativas" devem ser rejeitadas.
}

Muitos escritores pós-modernistas têm argumentado que qualquer "metanarrativa" relativa aos ideais educacionais gerais, relevantes a todas as pessoas, é suspeita ${ }^{8}$. Dentro da literatura pós-modernista mais ampla, Foucault e Lyotard são famosos por sua rejeição às metanarrativas. $\mathrm{Na}$ literatura da teoria da educação, Henry Giroux, por exemplo, vocaliza essa mesma objeção:

\begin{abstract}
Abstrações gerais que negam a especificidade e particularidade da vida cotidiana, que generalizam fora da existência do particular e do local, que suprimem a diferença sob a bandeira de categorias universalizantes são rejeitadas (por pós-modernistas sensatos) como totalitárias e terroristas (GIROUX, 1998, p.14).
\end{abstract}

Outros teóricos da educação também apoiam a objeção. Se bem sucedida, parece rebaixar a explicação oferecida acima sobre o interesse dos educadores pela argumentação, uma vez que ela depende exatamente de uma metanarrativa, concernente à racionalidade. Apoiar-se na metanarrativa Iluminista, então, não apenas falharia; também constituiria, nas palavras de Giroux, uma filosofia hegemônica "totalitária e terrorista", e, uma vez vista nessa luz, seria presumivelmente rejeitada tanto pelos filósofos "liberais" quanto pelos pós-modernos.

Essa objeção não é bem-sucedida. Por um lado, a metanarrativa relevante que trata da racionalidade não "nega a especificidade e a particularidade da vida cotidiana", "generaliza fora da existência do particular e o local" ou "suprime a diferença sob a bandeira de categorias universalizantes". Ela pode e deve reconhecer a especificidade e a particularidade, o particular e o local e a diferença. Ela deve e pode, além disso, aceitar que a diferença, a particularidade, a localidade e a especificidade são altamente relevantes para questões educacionais particulares. No entanto, apesar de a visão "modernista" aceitar e reconhecer essas particularidades e diferenças - não negando ou suprimindo diferenças, sendo, portanto, inocente das acusações articuladas por Giroux -, ele as toma como irrelevantes para certas questões, especialmente aquelas referentes à justificabilidade ou à correção dos princípios relevantes. Por exemplo, se é errado marginalizar, silenciar, ou oprimir membros de culturas minoritárias,

\footnotetext{
${ }^{8}$ A discussão nesta seção e na seção subsequente foram retiradas de Siegel (1995). Novamente, mudanças relevantes foram realizadas.
} 
EID\&A - Revista Eletrônica de Estudos Integrados em Discurso e Argumentação, Ilhéus, n. 11, jan/jun.2016.

então é errado fazê-lo - independentemente das particularidades das culturas vítimas de opressão. Portanto, a visão iluminista, presumida no que tange a racionalidade como um ideal educacional fundamental, reconhece a diferença e a particularidade, mas tem uma visão matizada da relevância da diferença: às vezes, é altamente relevante; em outras, não é. Essa visão rejeita a ideia de que a diferença é sempre relevante para tudo. Mas essa rejeição escapa à crítica de Giroux.

Ademais, a rejeição pós-moderna das metanarrativas é, em geral, notoriamente problemática. Como muitos autores perceberam, a própria rejeição constitui uma metanarrativa. Dizer que todas as metanarrativas devem ser rejeitadas, que todas são deficientes, é fazer uma afirmação universalizante do mesmo tipo que se afirma querer (universalmente) rejeitar. Entretanto, se rejeitar metanarrativas requer abraçar uma metanarrativa, então há uma dificuldade lógica inerente à própria ideia de rejeitá-las todas. A questão fundamental é: se a rejeição da metanarrativa requer uma metanarrativa, então a metanarrativa não pode ser (coerentemente) rejeitada universalmente. De outro modo, então, a afirmação de que a racionalidade é um ideal educacional fundamental não pode ser acertadamente criticada com base no fato de que se apoia numa metanarrativa.

\subsection{A concepção 'universalística' de racionalidade é em si problemática}

Uma acusação adicional feita contra a visão defendida aqui é que ela se baseia em uma concepção hegemônica de 'razão universal'. É verdade que essa visão pressupõe uma concepção particular de razão e racionalidade, de acordo com quais razões podem fornecer uma justificativa (ou garantia) objetiva para alegações particulares. Essa visão é 'universalística' no sentido de que a qualidade - o poder e a força probatória - das razões é universalmente aplicável: se $p$ é uma boa razão para $q$, então todos que, justificadamente, acreditam em $p$ e que acreditam em $q$ com base em $p$, acreditam, da mesma forma, justificadamente, em q. Particularidades e diferenças entre os crentes candidatos ou suas culturas não afetam a habilidade de $p$ em justificar $q$.

Eu já argumentei que a universalidade em si não é um alvo plausível de criticismo, uma vez que é necessária para sua própria rejeição, e, então, não pode ser, de forma coerente, rejeitada universalmente. Entretanto, diversos autores sugerem que há problemas especiais aqui para a universalidade da 
EID\&A - Revista Eletrônica de Estudos Integrados em Discurso e Argumentação, llhéus, n. 11, jan/jun.2016.

razão ou da racionalidade em particular. Não apenas diferentes culturas e pessoas avaliam razões particulares diferentemente em relação a suas forças probatórias - o que você ou sua cultura considera como uma boa razão para q, eu ou minha cultura consideramos como uma má razão -, mas um problema especial surge em relação à justificação daquela concepção de razão ou racionalidade em si. Como eu posso argumentar pela minha ou, de fato, qualquer concepção universalística de racionalidade? Se o fizer com base em razões que ofereço em sua defesa, pareço cometer uma petição de princípio contra aqueles que já não estão comprometidos com essa concepção; se o fizer com qualquer outra base, a justificativa ofertada falha pelas minhas próprias razões 9 . Assim, esses dois problemas ameaçam, de um outro ângulo, qualquer concepção universalística de racionalidade.

Ambos os problemas levantados são dificuldades epistemológicas fundamentais. Eu não posso possivelmente discuti-los aqui, apesar eles terem sido discutidos em outro lugar. Siegel (1987) destina-se a neutralizar a primeira e relativística dificuldade - isto é, que uma concepção universalística de racionalidade é defeituosa porque o poder e a força de condenação de razões parecem diferir de pessoa/cultura para pessoa/cultura. Siegel (1989) e (1992a) tenta oferecer uma justificativa racional - sem petição de princípio e não circular - de racionalidade em si. Se os esforços empreendidos em seus trabalhos são bem-sucedidos, então essas duas dificuldades com a 'razão universal' podem, pelo menos, ser resolvidas.

\subsection{Nós precisamos adotar o particular e, fazendo isso, rejeitar o universal}

Também foi argumentado que ideais educacionais, como tudo mais, são inevitavelmente e necessariamente particulares; que o particular e o universal são mutuamente exclusivos; e, consequentemente, que a tentativa de identificar os ideais educacionais 'universais', tal como racionalidade, é condenada ${ }^{10}$. Tal implicação é, contudo, ilusória, vou argumentar; o reconhecimento de que nosso ideal proposto é particular, dado que surge em um local histórico-cultural particular, de forma alguma exclui a sua universalidade.

\footnotetext{
9 N.T. Na versão original em inglês, "if I do so on any other basis, my proffered justification fails by my own lights".

${ }^{10}$ A discussão nesta subseção e na seguinte é retirada de Siegel (1995b); novamente, foram feitas alterações relevantes.
} 
A ideia de que particularidade e universalidade são mutualmente exclusivas e exaustivas, isto é, a ideia de que nós devemos optar por uma ou por outra, é claramente defendida no trabalho de Richard Rorty. Rorty contrasta "objetividade" - a visão de que, como pesquisadores filosóficos, nós devemos "andar fora de nossa comunidade o tempo suficiente para examiná-la à luz de algo que a transcenda, nomeadamente, aquilo que ela tem em comum com todas as outras comunidades humanas possíveis e reais", talvez "uma natureza humana a-histórica" (RORTY, 1989, p.36) - com "solidariedade", alegando que as pessoas localizam si mesmas em relação a alguma comunidade e que tanto a pesquisa quanto os pesquisadores são fundamentalmente "etnocêntricos" (ibidem, p.37). Rorty adota a solidariedade: "nós devemos, na prática, privilegiar nosso próprio grupo, ainda que não haja justificativa não circular para fazê-lo"; fazendo isso, ele adota "esse/seu isolado" provincialismo, essa admissão de que nós somos apenas o momento histórico em que estamos" (ibidem, p.44). Ele argumenta que empenhar-se atrás da objetividade é nada mais que "uma tentativa de evitar enfrentar a contingência" (ibidem, p.46).

Não desejo oferecer, aqui, qualquer tipo de crítica sistemática a Rorty, embora eu acredite que sua visão geral padeça de sérias dificuldades ${ }^{12}$. Quero, em vez disso, enfatizar que, adotando a solidariedade em detrimento da objetividade, Rorty rejeita o tipo de perspectiva trans-histórica e universalista que a tradição anterior - em sua perspectiva - se esforçava em articular e adotar. Ele sustenta que esse tipo de universalidade é filosoficamente insustentável e que a única alternativa para resolver é a solidariedade com particularidade não universalista (por exemplo, em RORTY, 1989a, p. 190-192). Em outros termos, ele sustenta que a dicotomia objetividade/solidariedade e, consequentemente, a dicotomia universalidade/particularidade, é exclusiva e

\footnotetext{
${ }^{11}$ N.T. Na versão original em inglês, "[t]his lonely provincialism, this admission that we are just the historical moment that we are". Devido a não correspondência gráfica entre as palavras "esse" e "seu" - como ocorre entre "this" e "his" -, optou-se por utilizar a barra (/) para apresentar as duas possibilidades de leitura.

${ }^{12}$ Em particular, não é claro o motivo para que aceitemos a reivindicação de Rorty de que a impossibilidade de objetividade ou universalidade segue da ou é ocasionada pela contingência especialmente à luz do fato de que a própria noção de implicação, da qual esse argumento depende, é em si apenas compreensível em termos universalistas, isto é, de tal modo que as premissas implicam a conclusão, independente de quem esteja considerando o argumento - claro que Rorty quer, algumas vezes, rejeitar a própria ideia que ele está argumentando (RORTY, 1989a, p. 44), apesar do fato de que sua escrita é cheia de argumentos e não seria inteligível sem a assunção de que ele está, de fato, engajado em argumentação. $\mathrm{O}$ argumento - linguagem, self e comunidade são contingentes; portanto, universalidade é impossível ou inatingível - é simplesmente um non sequitur.
} 
EID\&A - Revista Eletrônica de Estudos Integrados em Discurso e Argumentação, Ilhéus, n. 11, jan/jun.2016.

exaustiva; que, se deve adotar particularidade ou universalidade, mas não se podem adotar ambas. Isso está correto? Eu penso que não. Irei, a seguir, apresentar um argumento que pretende estabelecer a compatibilidade do universal com o particular.

Meu argumento é simples. O fato de que os seres humanos estão sempre localizados em um contexto cultural/histórico específico não enfraquece nossa habilidade coletiva de ir além do nosso contexto local e falar sobre preocupações de áreas e audiências mais amplas. Nós sempre julgamos da perspectiva de nossos próprios esquemas conceptuais; não há como escapar de todos os esquemas e julgar de um ponto de vista divino. Uma vez que nossos esquemas refletem nossas circunstâncias culturais/históricas, então essas circunstâncias constituem limites para o nosso julgamento; nós não podemos escapar deles inteiramente. Com essas premissas eu concordo. Mas alguns tiram delas a conclusão de que universalidade, ou uma perspectiva desembaraçada de nossa situação particular, é impossível; que nossos julgamentos não podem, em princípio, ter qualquer força além dos limites de nossa própria localização e de nossos próprios esquemas. Dessa conclusão eu discordo.

Não me alongarei acerca da dificuldade lógica óbvia de que forçar tal conclusão nas bases dessas (ou de quaisquer outras) premissas presume a legitimidade do mesmo tipo de universalidade que se está a rejeitar, uma vez que se acredita que a conclusão segue - para todos, julgando de seja qual for o esquema conceptual/cultural/histórico - a partir dessas premissas. Em vez disso, quero simplesmente defender que o argumento é um non sequitur, e que sua conclusão é falsa. Se todos os nossos julgamentos são feitos a partir da perspectiva de algum esquema que nós usemos, então, de acordo com esse argumento, nenhum dos nossos julgamentos tem tal legitimidade. Mas abundam contraexemplos a essa tese. Vários de nossos julgamentos aritméticos e matemáticos, por exemplo, embora feitos a partir de nossos esquemas, certamente têm legitimidade e estão corretos, apesar de crianças pequenas e membros de algumas outras culturas ${ }^{13}$ não compartilharem ou nossos esquemas ou nossos julgamentos. Teorias científicas importantes, de forma semelhante, têm aplicações e validade para além dos esquemas de

13 Por exemplo, os gregos antigos antes da invenção/descoberta dos números irracionais; matemáticos do século dezenove antes das descobertas de Cantor sobre os tamanhos de conjuntos infinitos; geômetras do século dezenove antes da descoberta das geometrias não Euclidianas; apostadores e pessoas de negócios de meia idade antes do desenvolvimento do cálculo de probabilidade moderno; etc. 
quem as inventou e de seus companheiros culturais - 'curvas' espaciais e massa ser convertível em energia, por exemplo, mesmo para aqueles cujos esquemas não sancionam esses julgamentos.

Contraexemplos à tese em discussão - que a legitimidade epistêmica do julgamento é limitada pela perspectiva do esquema a partir do qual o julgamento é feito - não estão restritos a domínios matemáticos e científicos. Julgamentos morais e sociais/políticos também aspiram a, e algumas vezes alcançam, legitimidade além do esquema: por exemplo, nosso julgamento de que opressão e marginalização são errados, embora realizados pela perspectiva de nosso próprio esquema, é considerado (por nós) como legítimo além das fronteiras daqueles que compartilham desse esquema. Similarmente, apesar de esquemas racistas, patriarcais e heterossexistas confirmarem formas associadas de marginalização e opressão, nós não temos dificuldade em criticar tais esquemas, ou os julgamentos realizados por meio deles, como inadequados ou injustos. De fato, advogar por qualquer valor moral/social/político é insistir sobre a legitimidade - independente do esquema ${ }^{14}$ - de tal crítica. Se nossas posturas em relação a tais valores não permitem isso, em que base nós podemos advogar e tentar garantir que os outros endossem tais valores e se adequem em relação a eles?15

O ponto central é esse: embora nós julguemos da perspectiva de nossos próprios esquemas, nossos julgamentos e sua legitimidade regularmente se estendem para além das fronteiras desses esquemas. Thomas McCarthy, discutindo sobre a concepção de verdade como aceitabilidade racional idealizada, como defendido por Hilary Putnam (1981), e utilizando a distinção “imanente/transcendente" de Putnam, articula o ponto como:

[...] qualquer consideração adequada da verdade como aceitabilidade racional terá de capturar não apenas sua imanência - isto é, seu caráter situado socialmente -, mas sua transcendência também. Embora nós possamos não ter ideia de padrões de racionalidade completamente independentes de práticas e linguagens historicamente concretas, a razão serve como um ideal em relação ao qual nós podemos criticar os padrões que herdamos. Ainda que nunca dissociados de práticas sociais de justificação, a ideia de razão não pode nunca

\footnotetext{
14 Eu uso aqui 'independência do esquema' não no sentido de não ser encaixado em nenhum esquema, mas particularmente no sentido de ter legitimidade e sentido além das fronteiras do esquema em que está encaixado.

15 É importante ressaltar que ideais universalistas iluministas, por exemplo, a dignidade da razão humana e o compromisso de decidir questões com base na razão, podem e devem ser entendidos desse modo. Esses ideais surgem e ganham circulação em circunstâncias históricas/culturais particulares (na Grécia antiga e na "Idade do Iluminismo" na Europa), mas esse fato em nada prejudica seja qual for a validade universal que eles apreciam.
} 
ser reduzida a qualquer conjunto particular de tais práticas. Do mesmo modo, a noção de verdade, enquanto essencialmente relacionada à assertividade garantida pelos padrões ou garantias dessa ou daquela cultura, não pode ser reduzida a qualquer conjunto particular de padrões ou garantias. Colocando isso de outra forma, nós podemos fazer, e tipicamente fazemos, alegações historicamente situadas e falíveis à validade universal" (MCCARTHY, 1988, p. 82).

\section{Como Putnam coloca:}

Se a razão é tanto transcendente quanto imanente, então a filosofia, como reflexão e argumentação culturalmente limitada sobre questões eternas, está tanto no tempo quando na eternidade. Nós não temos um ponto de Arquimedes; nós sempre falamos a língua de um tempo e de um lugar; mas o caráter certo ou errado do que nós falamos não é apenas para um tempo e um lugar (PUTNAM, 1982, p. 21).

Imanência não impede transcendência: como Putnam e McCarthy sugerem, nossos julgamentos, enquanto imanentes, ambicionam também pela transcendência. Não há dificuldade em achar que, ocasionalmente, eles atinjam a transcendência; nem há qualquer razão para pensar que é impossível, em princípio, que eles o possam. Consequentemente, o fato de nossos julgamentos serem imanentes não implica sua não transcendência. Assim, falham os argumentos de que imanência e transcendência são mutuamente exclusivas e exaustivas e de que, uma vez que não podemos escapar da imanência, devemos rejeitar a transcendência ${ }^{16}$.

Assim como imanência não implica a negação da transcendência, particularidade não implica a negação de universalidade. Nossos julgamentos e ideais inevitavelmente refletem a particularidade: eles são feitos por pessoas particulares, em circunstâncias históricas e culturais particulares. Mas esse fato, de modo algum, mina a universalidade de alguns de nossos ideais. Qualquer afirmação, de princípio universal ou qualquer outra coisa, será situada e localizada e refletirá as particularidades desse local; contudo, isso não leva à conclusão de que tais afirmações não sejam universais, seja em sua aplicabilidade seja em sua legitimidade. O particular e o universal não são mutuamente exclusivos; pelo menos alguns de nossos julgamentos são ambos. Se assim for, então nós estamos livres para considerar a racionalidade

\footnotetext{
${ }^{16}$ Eu apresso-me em observar que não advogo a ideia de que a verdade deveria ser entendida em termos de uma aceitabilidade racional ideal; eu prefiro a concepção, advogada por Putnam anteriormente, de verdade como "radicalmente não epistêmica" e como desconectada de considerações de aceitabilidade racional. Para uma discussão mais aprofundada, veja Siegel (1989a p. 132-133, passim).
} 
EID\&A - Revista Eletrônica de Estudos Integrados em Discurso e Argumentação, Ilhéus, n. 11, jan/jun.2016.

- a despeito das particularidades das circunstâncias de sua origem e de sua defesa- como um ideal educacional universal.

\subsection{O ideal da racionalidade é problematicamente opressivo e "masculino"; padrões supostamente "neutros" de racionalidade não são neutros}

Muitas filósofas feministas, como Susan Bordo, Genevieve Lloyd, Evelyn Fox Keller, Sandra Harding e Hilary Rose, têm argumentado que a "razão" é problematicamente "masculina"17. O argumento central é claramente articulado por Louise M. Antony e por Charlotte Witt:

Os desafios feministas realmente alcançaram o próprio “"núcleo duro’ do raciocínio abstrato", com a acusação de que os elementos mais fundamentais da tradição filosófica ocidental - os ideais de razão e de objetividade - estão tão profundamente corrompidos pelo patriarcado que eles devem ser intensamente transformados (se não totalmente abandonados) por qualquer filósofo comprometido com o desenvolvimento de concepções de conhecimento e de realidade adequadas aos objetivos transformativos do feminismo (ANTONY \& WITT, 1993, p. xiii) ${ }^{18}$.

E por Sally Haslanger:

[...] uma postura racional é ela própria uma postura de opressão ou de dominação, e ideais aceitos de razão tanto refletem quanto reforçam relações de poder que dão vantagem a homens brancos e privilegiados (HASLANGER, 1993, p.85)

E, numa discussão crítica de Catharine MacKinnon, por Elizabeth Rapaport (1993, p.129): "para MacKinnon, a racionalidade é uma inimiga a ser desmascarada e destruída".

MacKinnon desenvolve a questão:

O tipo de análise que tal feminino faz, e, especificamente, o padrão pelo qual ele é aceito como válido, é principalmente uma questão do critério que se adota para a adequação em uma teoria. Se o feminismo é uma crítica ao ponto de vista objetivo, entendido como masculino, então devemos repudiar as normas científicas padrão como critérios de adequação à nossa própria teoria, posto que o ponto de vista objetivo que nós criticamos é a postura científica. Em outras palavras, nossa crítica ao ponto de vista objetivo como masculino é uma crítica à ciência como uma abordagem do conhecimento especificamente masculina.

17 Entre várias outras fontes, ver os ensaios em Alcoff \& Potter (1993) e em Antony \& Witt (1993). Neste último, vários ensaios contestam essa hipótese.

${ }^{18}$ A citação encaixada é de Harding \& Hintikka (1983, p. ix) 
Com isso, nós repudiamos o critério masculino de verificação (MACKINNON, 1987, p. 54, dois últimos itálicos de Siegel) ${ }^{19}$

O que se segue à rejeição de "critérios masculinos"? Há apenas duas possibilidades: ou não há critério algum em termos dos quais as teorias podem ser avaliadas, ou há critérios diferentes aos quais se deve apelar na avaliação das teorias. A primeira é profundamente problemática; se não há critérios para avaliar teorias legitimamente, então a própria possibilidade da avaliação é rejeitada. Mas essa opção é contraproducente: se a avaliação em geral é rejeitada, então estamos impossibilitados de avaliar, ou de preferir racionalmente, as sugestões de que o critério masculino deva ser rejeitado ou de que a própria avaliação deva ser também rejeitada. Logo, não temos razão nenhuma para aceitar essas sugestões. A avaliação normativa não pode ser abandonada completamente; buscar fazê-lo seria, como Putnam (1982, p.20) sugere, tentar "suicídio mental". ${ }^{20}$

Por outro lado, a rejeição de critérios masculinos de avaliação teórica em favor de outros, incompatíveis, "critérios femininos", deve, por si só - se a preferência pelo último é defensável e não arbitrária - apoiar-se em (meta)critérios de acordo com os quais esses dois conjuntos rivais possam ser avaliados de maneira justa. Padrões e critérios são, dessa forma, necessários para a condução de qualquer empenho acadêmico sério, incluindo o de argumentar pela rejeição do ideal de racionalidade como preconceituoso e opressivo e, do mesmo modo, para a adesão a ideais feministas alternativos. Resumidamente, não se pode aderir coerentemente aos ideais do feminismo filosófico ou rejeitar como enviesado e opressivo o ideal "masculino" de racionalidade e, ao mesmo tempo, rejeitar padrões inteiramente ${ }^{21}$. E, a respeito da rejeição de MacKinnon aos padrões científicos e, portanto, à

\footnotetext{
19 Deve-se notar que, na visão de Mackinnon, a "racionalidade" é sinônimo de "objetividade"; ela não distingue as noções, mas rejeita a ambas (RAPAPORT, 1993, p. 129). MacKinnon (1987, p. 50) entende a objetividade como "ponto de vista não situado e distanciado"; como espero já ter esclarecido, não se trata do entendimento de que me valho aqui, uma vez que a situacionalidade não impossibilita (no meu entendimento) a objetividade. O que eu espero é um entendimento mais nuançado dos conceitos de racionalidade e de objetividade e de sua interrelação. Ver Neiman \& Siegel (1993).

20 Para uma discussão mais geral do caráter autossabotador da rejeição da avaliação normativa, ver Siegel (1987, 1996).

${ }^{21}$ Para discussão do caso geral, ver Siegel (1987). Antony (1993, esp. p. 190, p. 208-210) argumenta determinadamente que feministas radicais precisam reconhecer e utilizar uma concepção tradicional de verdade e de ideais tradicionais de objetividade e de imparcialidade, além de reconhecer (em maior ou menor grau) os padrões tradicionais de qualidade argumentativa filosófica e empírica, se pretendem alcançar tanto os objetivos do feminismo em particular, quanto do radicalismo político em geral.
} 
EID\&A - Revista Eletrônica de Estudos Integrados em Discurso e Argumentação, Ilhéus, n. 11, jan/jun.2016.

própria ciência, posto que masculinos, é difícil não ver isso como uma instância clássica de ir contra os próprios interesses. Consideremos, a esse respeito, a sugestão de Martha Nussbaum de que filósofas feministas se equivocam ao rejeitar razão e objetividade em seu empenho para combater o patriarcado:

Convenção e hábito são os inimigos das mulheres aqui, e a razão, seu aliado. 0 hábito decreta que o que parece estranho é impossível e "não natural"; a razão olha de frente para o estranho, recusando-se a presumir que o status quo corrente seja imutável ou "natural", em qualquer sentido normativo. $O$ apelo à razão e à objetividade constitui um pedido para que o observador se recuse a ser intimidado pelo hábito, e procure argumentos coerentes baseados em evidências que foram escrutinadas contra preconceito (NUSSBAUM, 1994, p.59)

Claramente, afirmar que padrões são necessários para a defesa racional do ideal da racionalidade, ou que padrões racionais são necessários para qualquer tipo de trabalho intelectual sério, não equivale a dizer que certos padrões, ou certos entendimentos deles, estão isentos de questionamentos críticos. Ao contrário, um dos maiores tipos de avanço intelectual é precisamente aquele que nos permite concluir que nossos padrões, ou nossas interpretações deles, têm sido, de uma maneira ou outra, deficientes e precisam de crítica e de melhoramento. De fato, uma das maiores contribuições dos estudos feministas tem sido precisamente estabelecer que certos padrões, ou certas aplicações destes, são problematicamente enviesados contra as mulheres. Mas não é possível rejeitar coerentemente certos padrões como enviesados e simultaneamente rejeitar padrões avaliativos em geral, ${ }^{22}$ posto que, fazendo-se isso, abandona-se a possibilidade de avaliação e, nesse caso, a rejeição de padrões rejeitados não é justificável/ada. Além disso, não se podem rejeitar todos os padrões e a própria possibilidade de avaliar e, ao mesmo tempo, aderir ao feminismo filosófico como um ideal ou como um padrão avaliativo de discursos e/ou teorias. Mas, se o movimento para rejeitar todos os padrões fracassa, então, de uma maneira ou de outra, os padrões de racionalidade serão inevitavelmente abraçados e endossados por todos que considerem seriamente a questão da justificabilidade dos padrões de racionalidade; e, nessa aderência, o ideal de racionalidade será endossado também. Consequentemente, o ideal sobrevive incólume a essa objeção em particular.

${ }^{22}$ Nem é sábio, conforme Nussbaum aponta (1994, p. 60-61), rejeitar um padrão com base em seu mau uso. No que se refere àqueles que "usam a alegação de objetividade para proteger seus julgamentos enviesados de escrutínio racional", Nussbaum escreve: "mais do que um pouco perversamente, algumas feministas culparam a própria norma de objetividade por esse comportamento, em vez de seus abusadores". 
EID\&A - Revista Eletrônica de Estudos Integrados em Discurso e Argumentação, Ilhéus, n. 11, jan/jun.2016.

\section{Conclusão}

Considerei, e apontei como falhos, cinco contestações ao ideal da racionalidade; argumentei que o ideal sobrevive aos desafios postos a ele por (1) a visão de Derrida sobre a indeterminação da linguagem, (2) a crítica às metanarrativas, (3) a crítica às concepções "universalistas" de racionalidade, (4) a incontornabilidade do particular e a exclusividade mútua do particular e do universal, e (5) a alegação feminista de que esse ideal seria opressivo e enviesado. Obviamente, lidei com esses desafios brevemente; muito mais precisa ser discutido a respeito de todos - e a respeito de outras questões também. No entanto, espero ter dito o suficiente para sugerir que o ideal não tem tantos problemas quanto seus críticos muitas vezes sugerem.

Assim, a ligação criada entre educação e argumentação, em termos de seu interesse/comprometimento conjunto no/com o ideal da racionalidade e a avaliação normativa das razões, é mantida - ao menos, provisoriamente. Desse modo, talvez tenha alcançado meu objetivo principal aqui: explicar por que educadores devem se preocupar com a argumentação.

\section{Referências}

ALCOFF, Linda; POTTER, Elizabeth (Eds). Feminist Epistemologies. New York: Routledge, 1993.

ANTONY, Louise M. Quine as Feminist: The Radical Import of Naturalized Epistemology. In: ANTONY, Louise M.; WITT, Carlotte E. A Mind of One's Own: Feminist Essays on Reason and Objectivity. Boulder: Westview Press, 1993.

ANTONY, Louise M.; WITT, Carlotte E. A Mind of One's Own: Feminist Essays on Reason and Objectivity. Boulder: Westview Press, 1993.

ARCILLA, René Vicente. For the Stranger in My Home: Self-Knowledge, Cultural Recognition, and Philosophy of Education. In: KOHLI, Wendy (Ed). Critical Conversations in Philosophy of Education. New York: Routledge, 1995, p.159-172.

BINKEY, Robert W. Can the Ability to Reason Well Be Taught?. In: BLAIR, J. A.; JOHNSON, R. H (Eds). Informal Logic: The First International Symposium. Inverness: Edgepress, 1980, p. 79-92.

BINKLEY, Robert W. Argumentation, Education and Reasoning. Informal Logic, Windsor, v. 17, n.2, p. 127-143, Spring 1995. 
BIRO, John.; SIEGEL, Harvey. Normativity, Argumentation and an Epistemic Theory of Fallacies. In: VAN EEMEREN, F. et al (Eds). Argumentation lluminated: Selected Papers from the 1990 International Conference on Argumentation. Amsterdam: SICSAT, 1992, p.85-103.

GIROUX, Henry. Postmodernism and the Discourse of Educational Criticism. Journal of Education, Boston, v. 170, n.3, p.5-30.

HARDING, Sandra.; HINTIKKA, Merrill B (Eds). Discovering Reality: Feminist Perspectives on Epistemology, Metaphysics, Methodology and Philosophy of Science. Dordrecht: D. Reidel, 1983.

HASLANGER, Sally. On Being Objective and Being Objectified. In: ANTONY, Louise M.; WITT, Carlotte E. A Mind of One's Own: Feminist Essays on Reason and Objectivity. Boulder: Westview Press, 1993, p. 85-125.

MACKINNON, Catharine. Feminism Unmodified: Discourses on Life and Law. Cambridge: Harvard University Press, 1987.

MCCARTHY, Thomas. Scientific Rationality and the 'Strong Program' in the Sociology of Knowledge. In: MCMULLIN, E (Ed.). Construction and Constraint: The Shaping of Scientific Rationality. Notre Dame, Indiana: University of Notre Dame Press, 1988, p. 75-95.

NEIMAN, Alven; SIEGEL, Harvey. Objectivity and Rationality in Epistemology and Education: Scheffler'S Middle Road. Synthese, v. 94, n. 1, p. 55-83, 1993.

NUSSBAUM, Martha. Feminists and Philosophy. The New York Review of Books, v. 41, n. 17, p. 59-63, October 1994.

PUTNAM, Hilary. Reason, Truth and History. Cambridge: Cambridge University Press, 1981.

.Why reason can't be naturalized. Synthese, v. 52, n. 1, p. 3-23, 1982.

RAPAPORT, Elizabeth. Generalizing Gender: Reason and Essence in the Legal Thought of Catharine MacKinnon. In: ANTONY, Louise M.; WITT, Carlotte E. A Mind of One's Own: Feminist Essays on Reason and Objectivity. Boulder: Westview Press, 1993, p. 127-143.

RORTY, Richard. Solidarity or Objectivity?. In: KRAUSZ, M (Ed.). Relativism: Interpretation and Corifrontation. Notre Dame: University of Notre Dame Press, 1989, p. 35-50.

$1989 a$.

. Contingency, Irony, and Solidarity. Cambridge: Cambridge University Press, 
EID\&A - Revista Eletrônica de Estudos Integrados em Discurso e Argumentação, Ilhéus, n. 11, jan/jun.2016.

SIEGEL, Harvey. Relativism Refuted: A Critique of Contemporary Epistemological Relativism. Dordrecht: D. Reidel Publishing Company, 1987.

. Educating Reason: Rationality, Critical Thinking, and Education. New York and London: Routledge, 1988.

. Why Be Rational? On THinking Critivally about Critical Thinking. Institute for Critical Thinking Resource Publication, New Jersey, série 2, n.1, p.1-15, Montclair State College 1989.

- Epistemology, Critical Thinking, and Critical Thinking Pedagogy. Argumentation, Países Baixos, v. 3, n. 2, p. 127-140, Kluwer Academic Publishers 1989 a.

. Education and the Fostering of Rationality. In: TALASKA, R (Ed.). Critical Reasoning in Contemporary Culture: Theoretical Perspectives on the Meaning, Conditions, and Goals of Critical Reasoning, New York: SUNY Press, 1992, p. 89-112;

. Rescher on the Justification of Rationality. Informal Logic, Windsor, v. 14, n. 1, p. 23-31, Spring 1992 .

. Gimme That Old-Time Enlightenment Meta-Narrative: Radical Pedagogies (and Politics). Require Old-Fashioned Epistemology (and Moral Theory). Inquiry: Critical Thinking Across the Disciplines, Huntsville: Sam Houston State University, v. 11, n. 4, p. 1, 17-22, 1993.

- 'Radical' Pedagogy Requires 'Conservative' Epistemology. Journal of Philosophy of Education, Salisbury, v. 29, n. 1, p. 33-46, 1995.

- Knowledge and Certainty; Feminism, Postmodernismo, and MultiCulturalism. In: KOHLI, Wendy (Ed.). Critical Conversations in Philosophy of Education. New York: Routledge, p. 190-200, 1995 a.

. What Price Inclusion?. In: NEIMAN, Alven (Ed.). Philosophy of Education 1995. Urbana, Illinois: Philosophy of Education Society, p. 1-22, 1995 b.

- Naturalism and the Abandonment of Normativity. In: O'DONOHUE, W; KITCHENER, R (Eds.). Psychology and Philosophy: Interdisciplinary Problems and Responses. London: Sage, no prelo.

; BIRO, John. Epistemic Normativity, Argumentation, and Fallacies. In: EEMEREN, F. van; et. al (Eds.). Analysis and Evaluation: Proceedings of the Third ISSA Conference on Argumentation, Amsterdam, June 1994. Amsterdam: SICSAT, p. 286299, 1995 . 
EID\&A - Revista Eletrônica de Estudos Integrados em Discurso e Argumentação, Ilhéus, n. 11, jan/jun.2016.

Tradução:

Gabriel Isola Lanzoni

Graduando em Língua Portuguesa e Linguística pela Universidade de São Paulo (USP)

Maria Gabriela Rodrigues de Castro

Bacharela em Língua Portuguesa e Linguística pela Universidade de São Paulo (USP)

Sergio Mikio Kobayashi

Mestrando pelo Programa de Filologia e Língua Portuguesa da Universidade de São Paulo (USP)

Winola Weiss Pires Cunha

Graduanda em Língua Portuguesa e Linguística pela Universidade de São Paulo (USP)

Forma de citação sugerida:

SIEGEL, Harvey. Por que os educadores devem preocupar-se com argumentação? Trad. Gabriel Isola Lanzoni; Maria Gabriela Rodrigues de Castro; Sergio Mikio Kobayashi; Winola Weiss Pires Cunha. EID\&A - Revista Eletrônica de Estudos Integrados em Discurso e Argumentação, Ilhéus, n. 11, p. 134-158, jan/jun.2016.

Recebido em: 02/03/2016

Aprovado em: 05/04/2016 